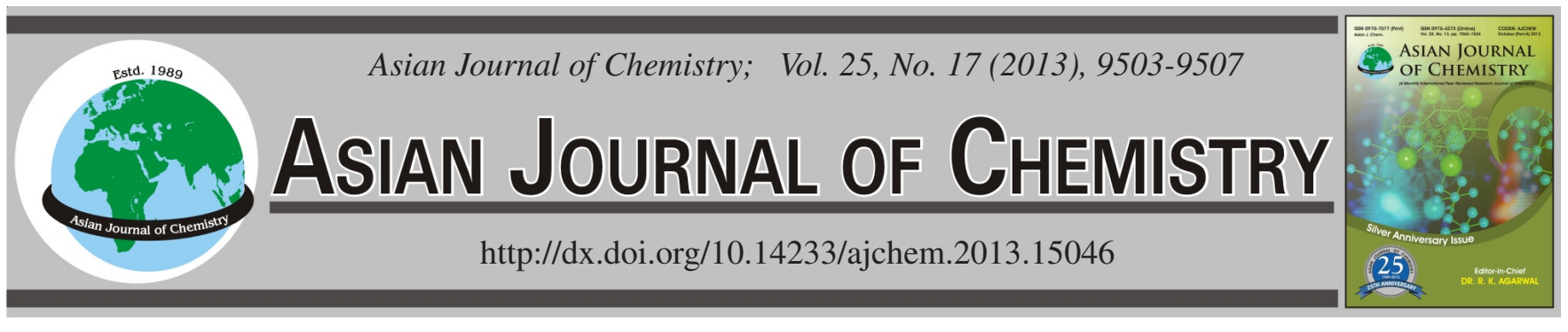

\title{
Extraction, Purification and Antiradical Activities of Alpinetin and Cardamomin from Alpinia katsumadai Hayata
}

\author{
H.T. LÜ ${ }^{1, *}$, Y.L. ZOU ${ }^{1}$, R. DenG ${ }^{2}$ and H. SHAN ${ }^{3, *}$
}

${ }^{1}$ College of Chemistry and Pharmaceutical Sciences, Qingdao Agricultural University, Qingdao, P.R. China

${ }^{2}$ Library, Qingdao Agricultural University, Qingdao, P.R. China

${ }^{3}$ Department of Animal Science and Technology, Qingdao Agricultural University, Qingdao, P.R. China

*Corresponding author: Tel./Fax: +86 532 86080540; E-mail: htlu6@sina.com

\begin{abstract}
Alpinetin and cardamomin are the major effective ingredients, which exist in Alpinia katsumadai Hayata and have strong activity in inhibiting platelet aggregation and tumor formation, antiinflammatory and antibacterial activities. Using orthogonal experiments $\mathrm{L}_{16}\left(4^{3}\right)$, alpinetin and cardamomin were extracted from Alpinia katsumadai Hayata by microwave-assisted extraction. Then, high-speed countercurrent chromatography (HSCCC) was used to separate and isolate of alpinetin and cardamomin by two-phase solvent system of $n$-hexane-ethyl acetate-ethanol-water (5:6:5:5, v/v) in one-step separation. The lower phase was used as the mobile phase in the head-totail elution mode. From $158.4 \mathrm{mg}$ of the crude extract, $14.47 \mathrm{mg}$ of alpinetin and $1.72 \mathrm{mg}$ of cardamomin with purities of 99.01 and 97.71 $\%$ were obtained, respectively. They were identified by melting points, UV, IR, ${ }^{1} \mathrm{H}$ and ${ }^{13} \mathrm{C}$ NMR. Furthermore, they were tested for $2,2-$ diphenyl-1-picrylhydrazyl (DPPH) free radicals scavenging activities. The results showed that alpinetin had strong DPPH free radicals scavenging activities.
\end{abstract}

Key Words: Alpinia, Cardamomin, Alpinia katsumadai Hayata, Purification, DPPH free radicals scavenging activities.

\section{INTRODUCTION}

Alpinia katsumadai Hayata have been used in traditional Chinese medicine as therapeutic drugs in the treatment of stomach disorders such as epigastric distension, nausea, vomiting and anorexia, which is safe for clinical administration due to its low toxicity ${ }^{1-4}$. Alpinia and cardamomin (Fig. 1) are the major effective ingredients, which exist in Alpinia katsumadai Hayata, belonging to flavonoids compounds. They are often used for inhibition of platelet aggregation and tumor formation, antiinflammatory bacteriostatic, etc. ${ }^{5,6}$. Therefore, an effective method for the isolation and purification of alpinia and cardamomin from Alpinia katsumadai Hayata is essential and urgent.

The commonly used methods for the separation and purification of flavonoids compounds are column chromatographies, including silica gel column chromatography, polyamide column chromatography, glucan gel column chromatography and preparative high performance liquid chromatography, etc. Among these methods, high-speed counter-current chromatography (HSCCC) has been widely applied for the isolation and purification of flavonoids compounds from traditional Chinese herbs and other natural products due to its unique advantages $^{7-12}$. High-speed counter-current chromatography is<smiles>COc1cc(O)cc2oc(-c3ccccc3)cc(=O)c12</smiles>

(1)

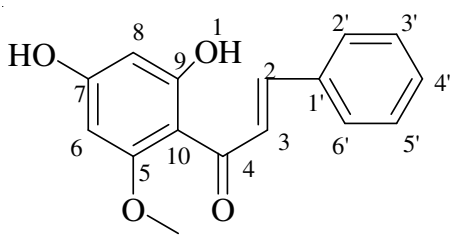

(2)

Fig. 1. Structures of (1) alpinetin and (2) cardamonin

a form of liquid-liquid partition chromatography without solid support that eliminates the irreversible adsorptive sample loss onto the solid support. It also has the unique features of high recovery, high efficiency and ease of scale-up.

In the present study, a high-speed counter-current chromatography method for fast separation and preparation of alpinia and cardamomin with high purities was successfully established. 
The extraction and isolation conditions were optimized. Their chemical structures were tested and confirmed by melting points, UV, IR, ${ }^{1} \mathrm{H}$ and ${ }^{13} \mathrm{C}$ NMR. In addition, the purified alpinetin and cardamomin were tested for DPPH free radicals scavenging activities.

\section{EXPERIMENTAL}

High-speed counter-current chromatography was performed using a TBE-300A high-speed counter-current chromatography unit (Shanghai Tauto Biotechnique Company, China) with a series of three multilayer preparative coils (i.d of the polytetrafluoroethylene tube $=1.6 \mathrm{~mm}$, total volume $=260$ $\mathrm{mL}$ ) and a $20 \mathrm{~mL}$ sample loop. The $\beta$ value ranged from 0.6 at the internal layer to 0.8 at the external layer, where $\beta=r / R$ with $r$ the distance from the coil to the holder shaft and $\mathrm{R}$ the revolution radius or the distance between the holder axis and central axis of the centrifuge. The revolution speed of the apparatus can be adjusted in the range between 0 and 1000 rpm. The HSCCC instrument was assembled by ÄKTA prime system (Amersham, USA) with a UV absorbance detector to monitor the effluent, a PrimeViewTM workstation (Amersham, USA) to collect the data and a MultiTemp III constant-temperature circulating implement (Thermo Heake GmbH, Germany) to control the separation temperature.

The HPLC system was an Agilent 1100 system, equipped with a G1311A solvent delivery unit, a G1314A UV detector, an Agilent temperature control module, a sample injector with $20 \mu \mathrm{L}$ injection loop, an Eclipse XDB- $\mathrm{C}_{18}(150 \mathrm{~mm} \times 4.6 \mathrm{~mm}$, i.d., $5 \mu \mathrm{m}$ ) analytical column and an Agilent HPLC workstation (Agilent Technologies, Santa Clara, CA, USA).

Alpinia, cardamomin and ritin were purchased from National Institutes for Food and Drug Control (Beijing, China). $n$-Hexane, ethyl acetate, ethanol, acetic acid, chloroform, n-butanol, methanol and 2,2-diphenyl-1-picrylhydrazyl (DPPH) were of HPLC grade and purchased from the Institute of Jinan Chemical Industry (China). Water used was purified by Cascada Laboratory Water Systems $(18.2 \mathrm{M} \Omega \mathrm{cm}$ ) (Pall Life Sciences, Ann Arbor, MI, USA). Alpinia katsumadai Hayata was purchased from local drug store in Qingdao, China.

Preparation of the crude sample: Using microwaveassisted method, the extraction conditions of alpinetin and cardamomin from Alpinia katsumadai Hayata were optimized by means of orthogonal tests. According to these experiments, Alpinia katsumadai Hayata was dried to constant weight and then pulverized to a powder. One gram of the powder was extracted two times (12 min for each time) with $24 \mathrm{~mL}$ of $100 \%$ ethanol (12 $\mathrm{mL}$ for each time) at $800 \mathrm{~W}$. Then, the extracts were combined and evaporated to dryness by rotary evaporation. The residues were suspended in $20 \mathrm{~mL}$ water by sonication and extracted with $20 \mathrm{~mL}$ ethyl acetate two times. All the ethyl acetate extracts were combined and concentrated to dryness by rotary evaporation. Finally, $158.4 \mathrm{mg}$ of the crude extract was obtained and stored at $-20{ }^{\circ} \mathrm{C}$ for subsequent HSCCC isolation and separation.

High-speed counter-current chromatography solvent system: A number of two-phase solvent systems were tested by changing the ratios of the individual solvents to obtain the optimum composition. The K values were determined according to the literature ${ }^{7}$. About $1 \mathrm{mg}$ of crude extract were put into a $10 \mathrm{~mL}$ test tube, to which $1 \mathrm{~mL}$ of each phase of the preequilibrated two-phase solvent system were added. The solution was shaken vigorously and then centrifuged. Both the upper phase and the lower phase were analyzed by HPLC. The $\mathrm{K}$ values of alpinia and cardamomin were obtained according to the peak areas by the equation: $K=A / B$, where A was the peak area of the upper phase, B was the peak areas of lower phase.

The two-phase solvent system was prepared by mixing $n$-hexane:ethyl acatate:ethanol:water (5:6:5:5, v/v) thoroughly equilibrated in a separation funnel at room temperature. Two phases were separated shortly before use and degassed by sonication for $10 \mathrm{~min}$.

High-speed counter-current chromatography separation: The multilayer coiled column was first completely filled with the upper (stationary) phase using the ÄKTA prime plus system. Then the apparatus was rotated at $850 \mathrm{rpm}$ in the head-to-tail elution mode and the lower phase was pumped into the column at a flow rate of $1.5 \mathrm{~mL} \mathrm{~min}^{-1}$. The separation temperature was set at $25^{\circ} \mathrm{C}$. After hydrodynamic equilibrium was reached, indicated by the emergence of the mobile phase front, $20 \mathrm{~mL}$ of the sample solution containing $158.4 \mathrm{mg}$ of the crude extract was injected. The effluent from the outlet of the column was continuously monitored at $280 \mathrm{~nm}$ and the chromatogram was recorded. Peak fractions were manually collected according to the chromatogram and analyzed by HPLC. Each fraction was evaporated to dryness under reduced pressure and stored at $4{ }^{\circ} \mathrm{C}$. After the separation was completed, the retention of the stationary phase relative to the total column capacity was computed from the volume of the stationary phase collected from the column.

Analysis and identification of target compound by HPLC: The crude extract and each fraction corresponding to various portions of the major peaks in HSCCC were analyzed by HPLC. The HPLC analysis was performed on an Agilent Eclipse XDB- $\mathrm{C}_{18}$ column $(150 \mathrm{~mm} \times 4.6 \mathrm{~mm}$, i.d., $5 \mu \mathrm{m})$ with gradient elution at a column temperature of $30^{\circ} \mathrm{C}$. The gradient elution began with $52 \%$ methanol, $48 \%$ acetic acid $(1 \%)$ for 16 min, then to $62 \%$ methanol, $38 \%$ acetic acid $(1 \%)$ and kept for $44 \mathrm{~min}$, finally returned to the initial conditions at a constant flow-rate of $1.0 \mathrm{~mL} / \mathrm{min}$. The peak elution was monitored at $286 \mathrm{~nm}$ fou the first $16 \mathrm{~min}$, then to $346 \mathrm{~nm}$. The purities of the collected fractions were determined by HPLC based on the peak area of the target species normalised to the sum of all observed peaks. The analytical curves of alpinetin and cardamomin were $\mathrm{c}(\mathrm{mg} / \mathrm{L})=5.6 \times 10^{-5} \times \mathrm{A}-2.1$ and $\mathrm{c}$ $(\mathrm{mg} / \mathrm{L})=1.1 \times 10^{-5} \times \mathrm{A}-2.1$, respectively, where $\mathrm{c}$ was the concentration of alpinetin or cardamomin and $\mathrm{A}$ was the peak area. Both of their linearities were in the concentration range of $2.0-200.0 \mathrm{mg} / \mathrm{L}$ with a correlation coefficient of 0.9999 .

Target compounds were identified by melting points, UV, IR, ${ }^{1} \mathrm{H}$ and ${ }^{13} \mathrm{C}$ NMR spectra as well as by comparing their HPLC retention time and UV spectra with those of the standards. The IR spectra were recorded on a Nicolet IR 200 spectrometer (USA). ${ }^{1} \mathrm{H}$ and ${ }^{13} \mathrm{C}$ NMR spectra were measured in dimethyl sulphoxide (DMSO)- $d_{6}$ on a JNM ECP-600 spectrometer (JEOL, Japan) with tetramethylsilane (TMS) as internal standard. 
DPPH free radical scavenging test: A solution of DPPH was prepared by dissolving $10 \mathrm{mg}$ DPPH in $1 \mathrm{~L}$ of anhydrous ethanol and the solution was kept in the dark at $4{ }^{\circ} \mathrm{C}$.

The potency of alpinetin and cardamomin in scavenging free radicals from DPPH was tested ${ }^{13}$. Rutin was prepared at $1 \mathrm{mg} / \mathrm{mL}$ as the reference standard. The percentages of free radicals scavenged by alpinetin, cardamomin and rutin were calculated. Concentrations of alpinetin, cardamomin and rutin that scavenged $50 \%$ of DPPH free radicals were interpolated from the graph of percentage of free radicals scavenged against sample concentration: $\mathrm{SE}_{\mathrm{DPPH}}=\left(\mathrm{A}_{\mathrm{c}}-\mathrm{A}_{\mathrm{s}}\right) / \mathrm{A}_{\mathrm{c}} \times 100 \%$, where $\mathrm{SE}_{\mathrm{DPPH}}$ is DPPH scavenging effect, $\mathrm{A}_{\mathrm{c}}$ is the absorbance at 517 $\mathrm{nm}$ of the control reaction containing all reagents except the test compound and $\mathrm{A}_{\mathrm{s}}$ is the absorbance at $517 \mathrm{~nm}$ of reaction containing test compound.

A dose response curve was plotted to determine the $\mathrm{IC}_{50}$ values. $\mathrm{IC}_{50}$ is defined as the concentration sufficient to obtain $50 \%$ of a maximum scavenging capacity. All tests and analyses were run in triplicate and averaged.

\section{RESULTS AND DISCUSSION}

Optimisation of sample extraction: An orthogonal $\mathrm{L}_{16}$ $\left(4^{5}\right)$ test design was applied to select the optimum extraction parameters of alpinetin and cardamomin from Alpinia katsumadai Hayata by microwave-assisted extraction. A combination of five factors (ethanol concentration, extraction time, number of repeat extractions, solid-liquid ratio and extraction power) with different levels was tested. Based on the results of these experiments (Table-1), the optimum extracting conditions were $100 \%$ ethanol, 12 times solidliquid ratio, power $800 \mathrm{~W}$, extracted $12 \mathrm{~min}$ and two times. After extracted with ethyl acetate, the contents of alpinetin and cardamomin were 10.15 and $1.27 \%$ in the crude extract, respectively (Fig. 2).

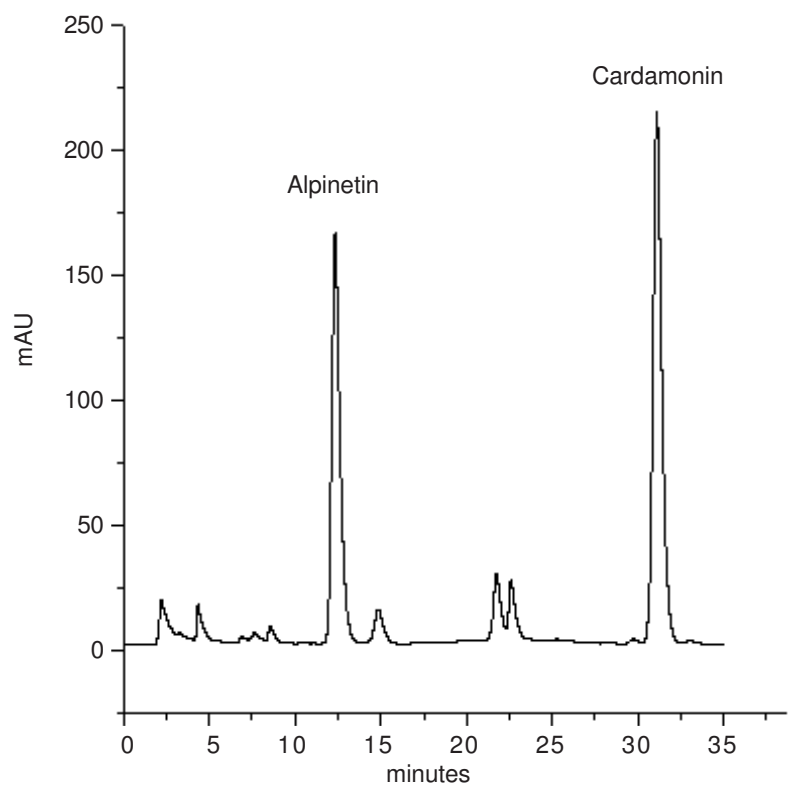

Fig. 2. HPLC chromatogram of the crude extract

Selection of solvent system: A series of experiments were performed to optimize the two-phase solvent system for HSCCC separation. All the selected two-phase solvent systems could form two phases with acceptable volume ratios to avoid wastage and the settling time was less than $20 \mathrm{~s}$. Among them, when chloroform:methanol:water, chloroform:methanol: $n$ butanol:water and $n$-hexane:ethanol:water were used as the two-phase solvent systems, their $\mathrm{K}$ values of alpinetin and cardamomin were very small. Alpinetin and cardamomin were quickly eluted from the column and could not be separated. When $n$-hexane:ethyl acetate:ethanol:water were used as the two-phase solvent system, it had acceptable K values. However, there is an unknown interfering compound, which might

\begin{tabular}{|c|c|c|c|c|c|c|c|c|}
\hline \multirow{3}{*}{ Test No. } & \multicolumn{7}{|c|}{$\begin{array}{c}\text { TABLE-1 } \\
\mathrm{L}_{16}\left(4^{5}\right) \text { ORTHOGONAL TEST RESULTS OF ALPINETIN AND CARDAMONIN }\end{array}$} & \\
\hline & \multirow{2}{*}{ A } & \multirow{2}{*}{ B } & \multirow{2}{*}{$\mathrm{C}$} & \multirow{2}{*}{$\mathrm{D}$} & \multirow{2}{*}{$\mathrm{E}$} & \multicolumn{3}{|c|}{ Content (mg/g) } \\
\hline & & & & & & Alpinetin & Cardamonin & Total \\
\hline 1 & 1 & 1 & 1 & 1 & 1 & 5.41 & 0.47 & 5.88 \\
\hline 2 & 1 & 2 & 2 & 2 & 2 & 7.54 & 0.95 & 8.49 \\
\hline 3 & 1 & 3 & 3 & 3 & 3 & 7.79 & 0.93 & 8.72 \\
\hline 4 & 1 & 4 & 4 & 4 & 4 & 8.85 & 0.90 & 9.75 \\
\hline 5 & 2 & 1 & 2 & 3 & 4 & 8.08 & 0.89 & 8.97 \\
\hline 6 & 2 & 2 & 1 & 4 & 3 & 7.65 & 0.80 & 8.45 \\
\hline 7 & 2 & 3 & 4 & 1 & 2 & 6.30 & 0.87 & 7.17 \\
\hline 8 & 2 & 4 & 3 & 2 & 1 & 7.60 & 0.87 & 8.47 \\
\hline 9 & 3 & 1 & 3 & 4 & 2 & 7.91 & 0.95 & 8.86 \\
\hline 10 & 3 & 2 & 4 & 3 & 1 & 7.56 & 0.95 & 8.51 \\
\hline 11 & 3 & 3 & 1 & 2 & 4 & 8.14 & 0.90 & 9.04 \\
\hline 12 & 3 & 4 & 2 & 1 & 3 & 7.32 & 1.08 & 8.30 \\
\hline 14 & 4 & 2 & 3 & 1 & 4 & 8.48 & 1.03 & 9.51 \\
\hline 15 & 4 & 3 & 2 & 4 & 1 & 8.23 & 0.83 & 9.06 \\
\hline 16 & 4 & 4 & 1 & 3 & 2 & 8.53 & 0.89 & 9.42 \\
\hline $\mathrm{K}_{1}$ & 8.21 & 8.20 & 8.20 & 7.74 & 7.98 & - & - & - \\
\hline $\mathrm{K}_{2}$ & 8.26 & 8.74 & 8.73 & 8.78 & 8.49 & - & - & - \\
\hline $\mathrm{K}_{3}$ & 8.70 & 8.50 & 8.89 & 8.91 & 8.67 & - & - & - \\
\hline $\mathrm{K}_{4}$ & 9.28 & 9.01 & 8.63 & 9.03 & 9.32 & - & - & - \\
\hline $\mathrm{R}$ & 1.07 & 0.81 & 0.69 & 1.29 & 1.33 & - & - & - \\
\hline
\end{tabular}


interfere the separation. The $\mathrm{K}$ values of alpinetin, cardamomin and a main unknown interfering compound were measured and summarised in Table-2. Among them, when $n$-hexane:ethyl acetate:ethanol:water (5:6:5:5, v/v) were used as the two-phase solvent systems, the $\mathrm{K}$ values of alpinetin and cardamomin were 1.05 and 4.37, respectively. Although the $\mathrm{K}$ values were not in the optimum range of $K=0.5-2.0$, the $K$ value between the target compound and the main unknown interfering compound was suitable. Alpinetin and cardamomin could be well separated.

\begin{tabular}{|c|c|c|c|}
\hline \multicolumn{4}{|c|}{$\begin{array}{c}\text { TABLE-2 } \\
\text { PARTITION COEFFICIENT (K) VALUES OF ALPINETIN, } \\
\text { CARDAMONIN AND A MAIN UNKNOWN INTERFERING } \\
\text { COMPOUND IN DIFFERENT PTOPORTION } \\
\text { OF } n \text {-HEXANE:ETHYL ACETATE:ETHANOL: } \\
\text { WATER SOLVENT SYSTEM }\end{array}$} \\
\hline $\begin{array}{l}\text { Proportion } \\
\text { (v/v) }\end{array}$ & $\begin{array}{l}\text { K value of } \\
\text { alpinetin }\end{array}$ & $\begin{array}{l}\mathrm{K} \text { value of } \\
\text { cardamonin }\end{array}$ & $\begin{array}{l}\text { K value of interfering } \\
\text { compound }\end{array}$ \\
\hline 1:1:1:1 & 0.71 & 3.51 & 8.59 \\
\hline $4: 8: 5: 3$ & 1.12 & 2.19 & 0.65 \\
\hline $2: 4: 3: 2$ & 0.84 & 2.10 & 0.13 \\
\hline $4: 7: 5: 3$ & 0.87 & 1.83 & 1.57 \\
\hline $5: 6: 5: 5$ & 1.05 & 4.37 & 3.37 \\
\hline $4: 6: 5: 3$ & 0.68 & 1.67 & 1.79 \\
\hline $10: 12: 10: 9$ & 0.87 & 3.17 & 9.10 \\
\hline 9:11:10:8 & 0.79 & 2.41 & 2.14 \\
\hline
\end{tabular}

Optimization of separation conditions by high-speed counter-current chromatography: The influences of separation temperature, flow rate of the mobile phase and revolution speed were investigated. Under the same conditions of revolution speed and flow rates, different temperatures (10, 20, 25 and $30^{\circ} \mathrm{C}$ ) were tested. When the temperature was set at 10 and $20^{\circ} \mathrm{C}$, the retention of the stationary phase was very small. When the temperature was set at $30^{\circ} \mathrm{C}$, the retention of the stationary phase was $41.79 \%$. But, cardamomin and the impurities could not be separated. When the temperature was set at $25^{\circ} \mathrm{C}$, the retention of the stationary phase was $51.11 \%$. Alpinetin and cardamomin could be well separated. Thus, $25^{\circ} \mathrm{C}$ was chosen as the separation temperature.

The flow rate of the mobile phase determines the separation time, the retention of the stationary phase and peak resolution ${ }^{14}$. The flow rate of mobile phase was adjusted from 1-3 mL/min. With a decrease the flow rate of the mobile phase, the retention of the stationary phase would increase and the separation would improve. However, it needed the longer separation time and the more mobile phase. When the flow rate was set at $2 \mathrm{~mL} /$ min, the retention of the stationary phase was $51.11 \%$ and alpinetin and cardamomin could be well separated.

The revolution speed of the coil tube had great influence on the retention of stationary phase and the use of a high rotary speed could increase the volume of the stationary phase retained in the column. However, high rotary velocity can damage the separation pipelines. In this experiment, the revolution speed was set at $850 \mathrm{rpm}$.

A $158.4 \mathrm{mg}$ quantity of the crude extract was dissolved in $20 \mathrm{~mL}$ of both upper and lower phases $(1: 1, \mathrm{v} / \mathrm{v})$ and separated according to the procedure described above. The upper phase was used as the stationary phase while the lower phase was used as the mobile phase in the head to tail elution mode. The total separation time was about $400 \mathrm{~min}$. The HSCCC fractions were analyzed by HPLC and their absorbance was measured to construct the elution curve (Fig. 3). Based on HPLC analysis and the elution curve of the preparative HSCCC, collected fractions were combined into different pooled fractions. A total of $14.47 \mathrm{mg}$ of alpinetin and $1.72 \mathrm{mg}$ of cardamomin was obtained and their HPLC chromatograms were shown in Fig. 3B-C. Based on the analytical curves of alpinetin and cardamomin, their purities were 99.01 and $97.71 \%$ and their recoveries were 90.01 and $85.70 \%$, respectively.
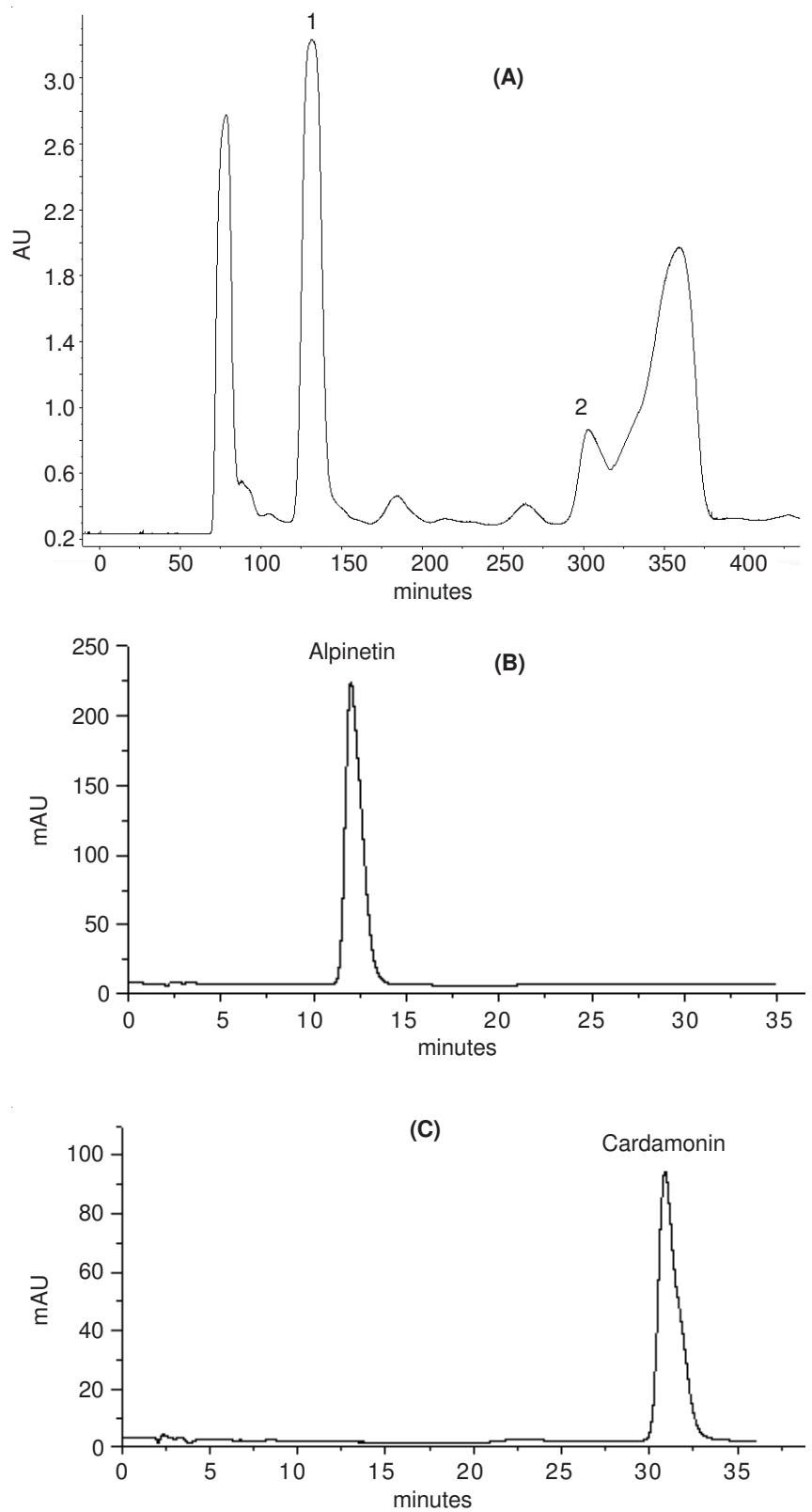

Fig. 3. HSCCC chromatogram of the crude extract (A) and HPLC chromatogram of the purified product (B) and (C)

Structural indentification: The chemical structures of peak fractions separated by HSCCC were identified according to their melting points, UV, FT-IR, ${ }^{1} \mathrm{H}$ and ${ }^{13} \mathrm{C}$ NMR. The data of each peak fraction were provided below.

Peak 1 in Fig. 3A: colourless needles, m.p. $223-225^{\circ} \mathrm{C}$, UV: $\lambda_{\max }(\mathrm{MEOH}): 286 \mathrm{~nm}$. FTIR $\left(\mathrm{cm}^{-1}\right): 3375.21(\mathrm{OH})$, 
$1607.28(\mathrm{C}=\mathrm{O}), 1607.28,1479(\mathrm{C}=\mathrm{C}, \mathrm{Ar}), 1211.52(\mathrm{Ar}-\mathrm{O}-\mathrm{C})$, 1107.38 (C-O-C). ${ }^{1} \mathrm{H}$ NMR (600 MHz, DMSO- $\left.d_{6}\right): 9.31(\mathrm{~s}$, $1 \mathrm{H}, 7-\mathrm{OH}$ ), 7.24-7.43 (m, 5H, 2'3'4'5'6'-H), 5.97-6.03 (q, 2H, 6,8-H), 5.34-5.37 (q, 1H, 2-H), 3.66-3.68 (d, 3H, 11-H), 2.512.85 (m, 2H, 3-H). ${ }^{13} \mathrm{C}$ NMR: 186.81 (4-C), 164.67 (7-C), 164.06 (5-C), 162.88 (9-C), 139.77 (1'-C), 128.53 (3'5'-C), 127.27 (4'-C), 126.28 (2'6'-C), 105.33 (10-C), 95.81 (8-C), 93.34 (6-C), 78.88 (2-C), 55.22 (11-C), 45.57 (3-C). On the basis of these results, the structure of target compound was identified as alpinetin ${ }^{15}$.

Peak 2 in Fig. 3A: orange needles, m.p. 205-208 ${ }^{\circ} \mathrm{C}$, UV: $\lambda_{\max }(\mathrm{MEOH}): 346 \mathrm{~nm}$. FTIR $\left(\mathrm{cm}^{-1}\right): 3150.74(\mathrm{OH}), 1622.15$ $(\mathrm{C}=\mathrm{O}), 1538,1482$ (C=C, Ar), 1209.32 (Ar-O-C), 1087 (C-O). ${ }^{1} \mathrm{H}$ NMR (600 MHz, DMSO-d $)$ : 14.02 (s, 1H, 9-OH), 9.42 (s, 1H, 7-OH), 7.87-7.91 (q, 1H, 3-H), 7.31-7.65 (m, 6H, 2,2'3'4'5'6'-H), 5.98 (s, 1H, 8-H), 5.97 (s, 1H, 6-H), 3.87 (s, 3H, 11-H). ${ }^{13} \mathrm{C}$ NMR: 192.26 (4-C), 168.12 (7-C), 167.57 (9-C), 164.97 (5-C), 141.76 (2-C), 135.56 (1'-C), 128.93 (3'5'C), 128.31 (4'-C), 127.68 (2'6'-C), 127.59 (3-C), 105.46 (10C), 96.02 (8-C), 91.34 (6-C), 55.54 (11-C). On the basis of these results, the structure of target compound was identified as cardamonin ${ }^{15}$.

DPPH free radical scavenging assay: The DPPH radical scavenging activities of alpinia, cardamomin and rutin were tested. The activities were increased by increasing the concentration of the samples. DPPH antioxidant assay is based on the ability of DPPH, a stable free radical, to decolorize in the presence of antioxidants. The DPPH radical contains an odd electron, which is responsible for the absorbance at $517 \mathrm{~nm}$ and also for a visible deep purple colour. When DPPH accepts an electron donated by an antioxidant compound, the DPPH is decolorized, which can be quantitatively measured from the changes in absorbance. The $\mathrm{IC}_{50}$ value of alpinia was 0.727 $\mathrm{mg} / \mathrm{mL}$, as opposed to that of rutin $\left(\mathrm{IC}_{50} 1.012 \mathrm{mg} / \mathrm{mL}\right)$, which is a well known antioxidant. However, cardamomin had very low DPPH radical scavenging activity, its $\mathrm{IC}_{50}$ value could not be determined.

\section{Conclusion}

Alpinetin and cardamomin were extracted from Alpinia katsumadai Hayata by microwave-assisted extraction. Using two-phase solvent system of $n$-hexane-ethyl acetate-ethanolwater $(5: 6: 5: 5, \mathrm{v} / \mathrm{v})$, they were isolated and purified by highspeed counter-current chromatography in one-step separation. From $158.4 \mathrm{mg}$ of the crude extract, $14.47 \mathrm{mg}$ of alpinetin and $1.72 \mathrm{mg}$ of cardamomin with purities of 99.01 and 97.71 $\%$ were obtained, respectively. Their structural identification was carried by UV, FTIR, ${ }^{1} \mathrm{H}$ and ${ }^{13} \mathrm{C}$ NMR. Alpinetin had strong DPPH free radicals scavenging activities.

\section{ACKNOWLEDGEMENTS}

This research was financially supported by Natural Science Foundation of Shandong Province, China (ZR2011CM024) and the National Key Technology R\&D Program of China (2011BAD34B03).

\section{REFERENCES}

1. J. Yang, Y. Dai, Y.F. Xia,W.Z. Huang and Z.T. Wang, Phytother. Res., 23, 267 (2009).

2. M.Y. Lee, N.H. Lee, C.S. Seo, J.A. Lee, D. Jung, J.H. Kim and H.K. Shin, Food Chem. Toxicol., 48, 1746 (2010).

3. S.E. Lee, H.T. Shin, H.J. Hwang and J.H. Kim, Phytother. Res., 17, 1041 (2003).

4. M.Y. Lee, C.S. Seo, J.A. Lee, I.S. Shin, S.J. Kim, H. Ha and H.K. Shin, Inflammation, 35, 746 (2012).

5. L. Liu, X. Chen and Z. Hu, Talanta, 71, 155 (2007).

6. A. Murakami, A. Kondo, Y. Nakamura, H. Ohigashi and K. Koshimizu, Biosci. Biotechnol. Biochem., 57, 1971 (1993).

7. Y. Ito and W.D. Conway, High-Speed Countercurrent Chromatography, Chemical Analysis 132, Wiley-Interscience, New York (1996).

8. T.Y. Zhang, Separation and Purification of Natural Products (Medicinal Herbs) by High-Speed Countercurrent Chromatography, Elsevier, Paris, p. 201 (2002).

9. R.M. Liu, Q.H. Sun, A.L. Sun and J.C. Cui, J. Chromatogr. A, 1072, 195 (2005).

10. H.T. Lü, J. Liu, R. Deng and J.Y. Song, Phytochem. Anal., 23, 637 (2012).

11. K. Xu, R. Deng and H.T. Lu, Asian J. Chem., 23, 3807 (2011).

12. E.D. Yuan, B.G. Liu, Z.X. Ning and C.G. Chen, Food Chem., 115, 1158 (2009)

13. A. Braca, N.D. Tommasi, L.D. Bari, C. Pizza, M. Politi and I. Morelli, J. Nat. Prod., 64, 892 (2001).

14. Y. Ito, J. Chromatogr. A, 1065, 145 (2005).

15. X.B. Wang, C.S. Yang, S.Z. Hua and L.Y. Kong, Chin. J. Nat. Med., 8, 419 (2010). 